trên lâm sàng. Phẫu thuật nội soi sau phúc mạc cắt nang thận là một phương pháp xâm lấn tối thiểu an toàn, đạt hiệu quả tốt, có tính thẫm mỹ cao, ít gây đau, thời gian phục hồi sớm và có thể tiến hành thường quy tại các cơ sở có trang bị phẫu thuật nội soi.

\section{TÀI LIÊU THAM KHẢO}

1. Steven Sussman, Sachio T. Cochran, col J J P a (1984). "Hyperdense renal masses: A CT manifestation of hemorrhagic renal cysts". Radiology, 150, 207-211.

2. Trân Chí Thanh (2002). Nghiên cứu chỉ định và kết quả điêu trị Nang thận đơn thuân bằng phương pháp soi ổ bunng cắt chỏm nang. Luận văn tốt nghiệp bác sỹ nội trú, Trường Đại Học Y Hà Nội

3. Trân Hiếu Hoc, Trân Quế Sơn (2017). "Phẩu thuật nội soi cắt chỏm nang thận đơn thuân tại Bênh viện Bach Mai.". Tạp chí phẫu thuật nội soi Việt Nam.sối tập 7 , 24-30.
4. Nguyễn Hoàng Đức, Nguyễn Hoàng Bắc, Trân Lê Linh Phương (2005). "Phương pháp cắt chỏm nang thận nội soi sau phúc mạc và qua phúc mạc". Tap chí YY học tp Hồ Chí Minh, Phụ bản số 1, Tập 9

5. Efesoy 0, Tek M, Bozlu M, et al (2015). "Comparison of single-session aspiration and ethanol sclerotherapy with laparoscopic de-roofing in the management of symptomatic simple renal cysts". Turk J Urol, 41 (1), 14-19.

6. Wiliam W. Roberts R B L, Karen E. Boyle and col. (2001). "Laparoscopic ablation of symptomatic parenchymal and peripelvic renal cysts". Urology, 58 , 165-169.

7. Lutter I, Weibl P, Daniel I, et al (2005). "Retroperitoneoscopic approach in the treatment of symptomatic renal cysts". Bratisl Lek Listy, 106, $366-370$.

8. Nguyê̂n Phú Viêt, Lê Anh Tuấn, Dương Xuân Hòa, Phạm Duy Hùng (2009) "Điều trị cắt chỏm nang đơn thân bằng phẩu thuât nội soi sau phúc mạc. 40 trường hợp". Tap chí $Y$ dược học quân sự,' số 8, tr 1-14.

\title{
ĐẶC ĐIỂM LÂM SÀNG VIÊM LỢI VÀ MộT Số YẾU TỐ LIÊN QUAN TRÊN BỆNH NHÂN ĐEO MẮC CÀI CHİNH NHA
}

\section{TÓM TẮT}

Mục tiêu: nghiên cứu tình trạng viêm lợi và một số yếu tố liên quan trên bênh nhân đeo mắc cài chỉnh nha. Đối tượng và phướng pháp: nghiên cứu được thực hiện trên 62 bệnh nhân đeo mắc cài có tình trang viềm lợi cần điều trị. Các đối tượng được khám lâm sàng để đánh giá chỉ số lợi (GI) và chỉ số mảng bám (PLI). Sử dụng thống kê y học để phân tích các kết quả nghiên cứu được. Kết quả: Không có sự khác biệt có ý nghĩa về giá trị trung bình (GTTB) các chỉ số theo giới và thời gian đeo mắc cài. Chỉ số GI ở nhóm BN dưới 18 tuổi cao hơn nhóm từ 18 tuổi trở lên, ở nhóm lấy cao răng trước đó trên 12 tháng cao hơn ở nhóm được lấy cao răng trong khoảng thời gian 6-12 tháng trước nghiên cứu $(p<0,05)$. Chỉ số GI và PLI cao nhất ở nhóm chải răng 1 lần/ngày, thấp hơn ở nhóm chải răng 2 lần/ngày và thấp nhất ở nhóm chải răng 3 lần/ngày, ở nhóm không có thói quen dùng các biện pháp hố trợ làm sạch răng cao hơn có ý nghĩa so với nhóm có dùng ít nhất 1 biện pháp hỗ trợ làm sạch răng $(p<0,05)$. Kết luận: Không có sự khác biệt về tình trang viêm lợi giữa nam và nữ. Mức đô viêm lợi ở lứa tuổi dưới 18 nặng hơn so với lứa tuổi trên 18. Tình trang viêm lợi có liên quan đến số lần chải răng trong ngày, thói quen dùng các biện pháp hỗ trợ làm sạch răng, khoảng thời gian lây cao răng định kỳ gần nhất,

*Bệnh viên RHM TU, Hà Nội

Chịu trách nhiệm chính: Ngỗ Thùy Linh

Email: linhngo.dds@gmail.com

Ngày nhận bài: 6/7/2021

Ngày phản biên khoa học: 1/8/2021

Ngày duyệt bài: 25/8/2021

\section{Ngô Thùy Linh*, Nguyễn Thị Hồng Minh* \\ nhưng không liên quan đến thời gian đeo mắc cài. \\ Tư khóa: Viêm lợi, mắc cài chỉnh nha \\ SUMMARY \\ CLINICAL CHARACTERISTICS OF GINGIVITIS AND SOME RELATED FACTORS IN PATIENTS WEARING ORTHODONTIC BRACES}

Objectives: To studygingivitis statusand some related factors in patients wearing orthodontic braces. Subjects and research methods: The study was conducted on 62 patients wearing braces with gingivitis requiring treatment. All patients were clinically examined for gingival index (GI) and plaque index (PLI). The result was analized by medical statistic software. Results: There was no significant difference in the mean value of indicators by gender and time of wearing braces. The GIindex of under 18 year -old group was higher than that of over 18 yearold group. The group of previous calculus removal over 12 months had GI index higher than group having calculus removed during $6-12$ months before the study $(p<0,05)$. The GI and PLI indexes were highest in the group brushing teeth once a day, lower in the group brushing twice a day, and lowest in the group brushing three times a day. These indexes of the group that did not have the habit of using supportive measures teeth cleaning was significantly higher than the group using at least 1 dental cleaning support $(p<0,05)$. Conclusion: There is no difference of gingival status between men and women. The gingivitis level of under 18 year -old group wasmore severe than that of over 18 year-old group. The gingivitis status was related to the brushing times a 
day, the habit of using teeth cleaning support, the nearest time of calculus removal but not related to the time of wearing braces.

Key words: Gingivitis, orthodontic braces

\section{I. ĐẶT VẤN ĐỀ}

Viêm lợi là tình trạng phổ biến ở bệnh nhân (BN) đeo mắc cài chỉnh nha. Một số nghiên cứu cho thấy từ sau ba tháng đặt khí cu chỉnh nha trở lên có ít nhất một loài vi khuẩn gây bênh quanh răng được tìm thấy ở mọi cá thể ${ }^{1}$. Nghiên cứu của J. Ramamurthy và cs (2020) cho thấy trong số các $\mathrm{BN}$ đeo mắc cài chỉnh nha có tới $76 \%$ trường hợp viêm lợi mạn tính thể toàn bộ². Các mắc cài, dây cung, khâu... trong chỉnh nha tạo nên những vùng lưu giữ làm tăng tích tụ mảng bám, gây khó khăn cho việc vệ sinh răng miêng. Bên canh đó,mức độ ảnh hưởng tới tỉ lệ mắc và mức độ tiến triển của viêm lợido mỗi yếu tố là khác nhau. Vì thế, chúng tôi tiến hành nghiên cứu đề tài với muc tiêu: mô tả đặc điểm lâm sàng viêm lợi và một số yếu tố liên quan trên bệnh nhân đeo mắc cài chỉnh nha tại Bệnh viện Rănng Hàm Mặt Trung ương Hà Nội.

\section{II. ĐỐI TƯỢNG VÀ PHƯƠNG PHÁP NGHIÊN CỨU \\ 2.1. Đối tượng nghiên cứu}

Tiêu chuẩn lựa chọn: Là những $B N$ đang đeo mắc cài chỉnh nha cả 2 hàm ít nhất 3 tháng trước khi tham gia nghiên cứu, có biểu hiện viêm Iợi cần điều tri.

Tiêu chuẩn loại trừ: BN không đồng ý tham gia nghiên cứu, không hợp tác điều trị; đang mang thai hoặc cho con bú; bị viêm quanh răng tiến triển nhanh ở thanh thiếu niên; bi mắc các bệnh toàn thân hoặc cấp tính khác; đang được điều trị viêm lợi hoặc sử dụng thuốc kháng sinh.

\subsection{Thời gian và đia điểm}

- Thời gian: Từ tháng 7/2020 đến tháng 7/2021.

- Địa điểm: khoa Nha chu và khoa Nắn chỉnh răng - Bệnh viện Răng Hàm Mặt TW Hà Nội.

\subsection{Phương pháp nghiên cứu}

- Thiết kế nghiên cứu: Mô tả cắt ngang.

- Mẫu nghiến cứu: Gồm 62 BN, chọn mẫu thuận tiện dựa theo tiêu chuẩn lựa chọn và loại trừ, khám lần lượt đến khi đạt được cỡ mẫu cần có thì dừng lai.

- Phương pháp thu thập số liệu: Hỏi bệnh và khám lâm sàng những $B N$ theo tiêu chuẩn lựa chọn: bao gồm các thông tin hành chính, khảo sát thói quen, ý thức vệ sinh răng miệng và đánh giá, ghi nhận các chỉ số GI, PLI trên tất cả các răng trong miệng ${ }^{3}$, trừ răng số 8.

- Xử lý và phân tích số liệu: Tất cả bênh án nghiên cứu sau khi thu thập sẽ được mã hóa, nhập và phân tích số liệu theo phần mềm thống kê SPSS 16.0

- Đạo đức nghiên cứu: Đối tượng quyết định tham gia nghiên cứu hoàn toàn tự nguyện và các nội dung điều tra chỉ được tiến hành khi được sự đồng ý của đối tượng. Trong quá trình điều tra, đối tượng có quyền không tiếp tục tham gia nữa và có thể rút khỏi nghiên cứu bất kỳ lúc nào.

\section{KẾT QUẢ NGHIÊN CỨU}

3.1. Đặc điểm lâm sàng viêm lợi trên bệnh nhân đeo mắc cài chỉnh nha. Qua nghiên cứu trên $62 \mathrm{BN}$ đeo mắc cài chỉnh nha có tình trang viêm lợi, chúng tôi bước đầu thu được một số kết quả như sau: Nhóm đối tượng nghiển cứu có tuổi nhỏ nhất là 10 , cao nhất là 31 tuổi,

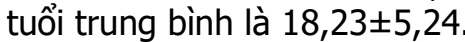

Trong số 62 đối tượng tham gia nghiên cứu, có 29 đối tượng là nam chiếm $46,8 \%$ và 33 đối tượng là nữ chiếm $53,2 \%$.

Bảng 1. Giá trị trung bình các chỉ số lâm sàng theo giới

\begin{tabular}{|c|c|c|c|}
\hline Chỉ số & $\begin{array}{c}\text { Nam } \\
(\mathbf{n = 2 9 )}\end{array}$ & $\begin{array}{c}\mathbf{N} \text { ữ } \\
(\mathbf{n = 3 3 )}\end{array}$ & $\mathbf{p}$ \\
\hline GI & $1,24 \pm 0,28$ & $1,25 \pm 0,27$ & 0,906 \\
\hline PLI & $2,34 \pm 0,19$ & $2,36 \pm 1,59$ & 0,707 \\
\hline
\end{tabular}

Kết quả cho thấy không có sự khác biệt có ý nghĩa về GTTB các chỉ số lâm sàng theo giới ( $>>0,05)$.

Bảng 2. Giá trị trung bình các chỉ số lâm sàng theo tuổi

\begin{tabular}{|c|c|c|c|}
\hline Chỉ số & $\begin{array}{c}\text { <18 tuối } \\
(\mathbf{n = 3 1 )}\end{array}$ & $\begin{array}{c}\mathbf{2 1 8} \text { tuốí } \\
(\mathbf{n = 3 1 )}\end{array}$ & $\mathbf{p}$ \\
\hline GI & $1,33 \pm 0,27$ & $1,16 \pm 0,25$ & $\mathbf{0 , 0 1 4}$ \\
\hline PLI & $2,38 \pm 0,15$ & $2,32 \pm 0,19$ & 0,132 \\
\hline
\end{tabular}

GTTB chỉ số GI ở nhóm đối tượng dưới 18 tuổi cao hơn so với nhóm trên 18 tuổi. Sự khác biệt có ý nghĩa thống kê với $p<0,05$.

3.2. Yếu tố liên quan tình trạng viêm lợi trên bệnh nhân đeo mắc cài chỉnh nha

Bảng 3. Giá trị trung binh các chỉ số lâm sàng theo số lần chải răng trong ngày

\begin{tabular}{|c|c|c|c|c|}
\hline $\begin{array}{c}\text { Chỉ } \\
\text { số }\end{array}$ & $\begin{array}{c}\mathbf{1} \text { lần } \\
\mathbf{( n = 6 )} \\
\mathbf{9 , 7 \%}\end{array}$ & $\begin{array}{c}\mathbf{2} \text { lần } \\
\mathbf{( n = 4 7 )} \\
\mathbf{7 5 , 8 \%}\end{array}$ & $\begin{array}{c}\mathbf{3} \text { lần } \\
\mathbf{( n = 9 )} \\
\mathbf{1 4 , 5 \%}\end{array}$ & $\mathbf{p}$ \\
\hline GI & $1,57 \pm 0,21$ & $1,24 \pm 0,26$ & $1,02 \pm 0,22$ & 0,0001 \\
\hline PLI & $2,55 \pm 0,12$ & $2,34 \pm 0,17$ & $2,27 \pm 0,13$ & 0,003 \\
\hline
\end{tabular}

Phân lớn đối tượng chải răng 2 lần/ ngày $(75,8 \%)$, chỉ có $9,7 \%$ BN chải răng 1 lần/ngày và $14,5 \% B N$ chải răng 3 lần/ngày. Chỉ số $G I$ và PLI cao nhất ở nhóm chải răng 1 lần/ngày, thấp hơn ở nhóm chải răng 2 lần/ngày và thấp nhất ở nhóm chải răng 3 lần/ngày. Sự khác biệt có ý nghĩa thống kê với $p<0,05$. 
Bảng 4. Giá trị trung bình các chỉ số lâm sàng theo thói quen dùng các biện pháp hố trợ làm sạch răng

\begin{tabular}{|c|c|c|c|}
\hline $\begin{array}{c}\text { Chí } \\
\text { số }\end{array}$ & $\begin{array}{c}\text { Có dùng } \\
(\mathbf{n = 3 6 )} \\
\mathbf{5 8 , 1 \%}\end{array}$ & $\begin{array}{c}\text { Không dùng } \\
(\mathbf{n = 2 6 )} \\
\mathbf{4 1} \mathbf{9} \%\end{array}$ & $\mathbf{p}$ \\
\hline GI & $1,15 \pm 0,25$ & $1,37 \pm 0,25$ & 0,001 \\
\hline PLI & $2,28 \pm 0,17$ & $2,44 \pm 0,14$ & 0,0001 \\
\hline
\end{tabular}

Trong số 62 đối tượng nghiên cứu có 36 đối tượng $(58,1 \%)$ có sử dụng ít nhất 1 biện pháp hỗ trợ làm sạch răng như chỉ tơ, bàn chải kẽ, tăm nước... và 26 đối tượng $(41,9 \%)$ không sử dụng biện pháp hỗ trợ nào.

GTTB các chỉ số GI và PLI ở nhóm không có thói quen dùng các biện pháp hỗ trợ làm sạch răng cao hơn đáng kể so với nhóm có sử dụng $(p<0,05)$

Bảng 5. Giá trị trung binh các chỉ số lâm sàng theo khoảng thời gian lấy cao răng định kỳ gần nhất

\begin{tabular}{|c|c|c|c|}
\hline Chỉ số & $\begin{array}{c}\mathbf{6}-\mathbf{1 2} \text { tháng } \\
(\mathbf{n = 2 3}) \\
\mathbf{3 7 , 1 \%}\end{array}$ & $\begin{array}{c}\mathbf{> 1 2} \text { tháng } \\
\mathbf{( n = 3 9 )} \\
\mathbf{6 2 , 9} \mathbf{9}\end{array}$ & $\mathbf{p}$ \\
\hline GI & $1,14 \pm 0,22$ & $1,31 \pm 0,28$ & 0,018 \\
\hline PLI & $2,32 \pm 0,20$ & $2,37 \pm 0,16$ & 0,235 \\
\hline
\end{tabular}

Trong số nhóm nghiên cứu có 23 đối tượng $(37,1 \%)$ được lấy cao răng trước thời điểm nghiên cứu trong khoảng thời gian 6 - 12 tháng và 39 đối tượng $(62,9 \%)$ được lấy cao răng trước đó trên 12 tháng.

GTTB của chỉ số GI ở nhóm lấy cao răng trước đó trên 12 tháng cao hơn ở nhóm được lây cao răng trong khoảng thời gian $6-12$ tháng trước nghiên cứu. Sự khác biệt có ý nghĩa thống kê với $\mathrm{p}<0,05$.

Bảng 6. Giá trị trung binh các chỉ số lâm sàng theo thời gian đeo mắc cài

\begin{tabular}{|c|c|c|c|c|}
\hline $\begin{array}{c}\text { Chỉ } \\
\text { số }\end{array}$ & $\begin{array}{c}\mathbf{3 - 6} \\
\text { tháng } \\
\mathbf{( n = 5 )} \\
\mathbf{8 , 1 \%}\end{array}$ & $\begin{array}{c}\mathbf{6 - 1 2} \\
\text { tháng } \\
\mathbf{( n = 1 4 )} \\
\mathbf{2 2 , 6 \%}\end{array}$ & $\begin{array}{c}\mathbf{1 2} \\
\text { tháng } \\
\mathbf{( n = 4 3 )}\end{array}$ & $\mathbf{6}$ \\
\hline GI & $1,27 \pm 0,93$ & \\
\hline PLI & $2,35 \pm 0,18$ & $2,29 \pm 0,29$ & $1,22 \pm 0,28$ & 0,702 \\
\hline
\end{tabular}

Kết quả cho thấy không có sự khác biệt về GTTB của các chỉ số lâm sàng theo thời gian đeo mắc cài $(p>0,05)$.

\section{BÀN LUÂN}

Trong nghiên cứu này chúng tôi đánh giá tình trạng viêm lợi của bệnh nhânđeo mắc cài chỉnh nha với các chỉ số GI, PLI theo đặc điểm và hành vi chăm sóc răng miệng của đối tượng bao gồm các yếu tố tuổi, giới, số lần chải răng trong ngày, thói quen dùng các biện pháp hỗ trợ làm sạch răng, khoảng thời gian lấy cao răng định kỳ gần nhất và thời gian đeo mắc cài để từ đó đưa ra mối liên quan của các yếu tố này với tình trạng viêm lợi.

Tuổi trung bình của nhóm nghiên cứu là $18,23 \pm 5,24$. Đối tượng nghiên cứu của chúng tôi có tuổi trung bình không cao, bởi các BN hiện nay ngày càng được quan tâm, tư vấn can thiệp điều trị từ sớm và lứa tuổi hoc sinh được phu huynh cho đi điều trị chỉnh nha chiếm tî lệ lớn trong số các BN chỉnh nha.

Bảng 1 cho thây không có sự khác biệt các chỉ số giữa nam và nữ. Kết quả này cũng phù hợp với nghiên cứu của Rakhshan và cs khi đánh giá ảnh hưởng của chỉnh nha cố định và giới tính lên sự tích tụ của mảng bám răng ${ }^{4}$. Điều đó chứng tỏ yếu tố giới không liên quan đến tình trạng viêm lợi.

Bảng 2 cho thấy có mối liên quan giữa mức độ viêm lợi và tuổi BN.Kết quả này cũng tương tự với nghiên cứu của Akkaya và cs khi đánh giá ảnh hưởng của chỉnh nha cố định lên tình trạng lợi giữa thanh thiếu niên và người trưởng thành, tỉ lệ viêm lợi ở nhóm thanh thiếu niên cao hơn đáng kể so với nhóm còn laij ${ }^{5}$.Điều này là do hầu hết ở lứa tuổi dưới $18 \mathrm{BN}$ còn đang trong giai đoạn tăng trưởng, nhiều BN đang ở tuổi dậy thì. Đây là giai đoạn cơ thể nhạy cảm, thường đi kèm với phản ứng quá mức của lợi đối với mảng bám do ảnh hưởng của các hormon giới tính ${ }^{6}$. Các yếu tố tại chỗ thông thường gây ra các phản ứng tương đối nhẹ nhưngở tuổi dậy thì có thể dẫn đến tình trang viêm rõ rệt, lợi sưng nề, phì đại. Do đó, mặc dù chỉ số mảng bám giữa 2 nhóm tuổi không có khác biệt đáng kể, nhưng chỉ số viêm lợi ở nhóm tuổi dưới 18 vẫn cao khác biệt so với nhóm trên 18 tuổi.

Bảng 3 cho thấy có mối liên quan giữa mức độ viêm lợi và số lần chải răng trong ngày. Điều này cũng phù hợp với $B N$ viêm lợi nói chung và tình trang viêm lợi trên $\mathrm{BN}$ đeo mắc cài chỉnh nha nói riêng. Việc vệ sinh đều đặn trong ngày sau các bữa ăn làm giảm vị trí và số lượng mảng bám răng, từ đó làm giảm sự phơi nhiễm của lợi với mảng bám vi khuẩn, và vì thế mức độ viêm lợi cũng giảm hơn.

Kết quả ở bảng 4 cũng phù hợp với nghiên cứu của Manuel và $\mathrm{CS}$, ở những $\mathrm{BN}$ đeo mắc cài chỉnh nha, việc chải răng dù đúng kỹ thuật cũng chỉ làm sạch hiệu quả được khoảng $60 \%$ bề mặt răng, đòi hỏi phải dùng thểm dụng cụ hỗ trợ khác để làm sạch khu vực mặt bên răng, do các khí cụ này làm lưu giữ cặn thức ăn ở những vị trí mà bàn chải thông thường không làm sạch tới được $c^{7}$. Do đó có thể nói, việc dùng biện pháp hỗ trợ làm 
sach răng sẽ giúp làm giảm đáng kể mức độ mảng bám và viêm lợi cho bệnh nhân chỉnh nha.

Bảng 5 cho thấy có mối liên quan giữa mức độ viêm lợi và khoảng thời gian lấy cao răng định kỳ gần nhất. Kết quả này cũng tương đồng với báo cáo của Mahindra RK và cS, tỉ lệ viêm lợi tăng lên đáng kể ở nhóm $B N$ chỉnh nha mà không đến khám vệ sinh răng miệng trong quá trình điều trị? Còn mảng bám răng được hình thành và tích lũy hàng ngày, phụ thuộc vào thói quen, tần suất, cách thức vệ sinh răng miệng chứ không phụ thuộc vào việc lấy cao răng trước đó.

Kết quả ở bảng 6 cho thấy thời gian đeo mắc cài không ảnh hưởng đến mức độ viêm lợi của $B N$. Có thể nói, mức độ mảng bám răng và viêm Iợi phụ thuộc vào ý thức, cách thức, tần suất vệ sinh răng miệng của $B N$ mà không phụ thuộc vào thời gian chỉnh nha của $\mathrm{BN}$. Ở những $\mathrm{BN}$ có thời gian chỉnh nha kéo dài, nếu $B N$ vẫn duy trì được việc vệ sinh răng miệng hàng ngày và định kỳ thì sẽ có thể duy trì được chỉ số lợi và mảng bám ở mức tốt.

\section{KẾT LUẬN}

- Không có sự khác biệtvề tình trạng viêm lợi giữa nam và nữ trong nhóm nghiên cứu .

- Mức độ viêm lợi ở lứa tuổi dưới 18 nặng hơn so với lứa tuổi trên 18.

- Ở bệnh nhân đeo mắc cài chỉnh nha, tình trạng viêm lợi có liên quan đến số lần chải răng trong ngày, thói quen dùng các biện pháp hỗ trợ làm sạch răng, khoảng thời gian lấy cao răng định kỳ gần nhất, nhưng không liên quan đến thời gian đeo mắc cài.

\section{TÀI LIÊU THAM KHẢO}

1. Contaldo $\mathbf{M}$, Lucchese $A$, Lajolo $\mathbf{C}$, et al. The Oral Microbiota Changes in Orthodontic Patients and Effects on Oral Health: An Overview. Journal of Clinical Medicine. 2021;10(4):780. doi:10.3390/jcm10040780

2. Mahindra RK, Suryawanshi GR, Doshi UH. Effects of fixed orthodontic treatment on gingival health: An observational study. International Journal of Applied Dental Sciences.:6.

3. Nha Khoa Cộng Đồng. Vol 1. Nhà xuất bản Giáo dục Việt Nam; 2016.

4. Rakhshan $\mathbf{H}$, Rakhshan V. Effects of the initia stage of active fixed orthodontic treatment and sex on dental plaque accumulation: A preliminary prospective cohort study. The Saudi Journal for Dental Research. 2015;6(2):86-90. doi:10.1016/j.sjdr.2014.09.001

5. Akkaya M. Are the Effects of Fixed Orthodontic Treatment on Gingival Health Similar in Adolescents and Young Adults? Journal of Biomedical Sciences. 2016;6(1):5.

6. Tevatia S. Puberty Induced Gingival Enlargement. BJSTR. $2017 ; 1(1)$ doi:10.26717/BJSTR.2017.01.000126

7. $\mathbf{R}$ MD la $\mathbf{R}$, Guerra JZ, Johnston DA, Radike AW. Plaque Growth and Removal With Daily Toothbrushing. Journal of Periodontology. 1979;50(12):661-664.

doi:10.1902/jop.1979.50.12.661

\section{KẾT QUẢ PHẪU THUÂT TAQO HÌNH NƠ VI HẮC TỐ BẨM SINH VÙNG MẶT Cổ}

\section{Chanthavy Souksavarn*, Trần Thiết Sơn,* Tạ Thị Hồng Thúy*, Dương Đại Hà*}

\section{TÓM TẮT}

Bài báo nhằm đánh giá kết quả phẫu thuật tạo hình nơ vi hắc tố bẩm sinh vùng mặt cổ. Nghiên cựu trên 36 bệnh nhân (16 nam và 20 nữ̛) với 45 lần phẫu thuật từ 1/2015 đến 5/2020 tại khoa Phẫu thuật tạo hình - Bệnh viện Xanh Pôn Hà Nội. Kết quả cho thấy đặc điểm nơ vi hắc tố bẩm sinh vùng mặt cổ rấtđa dạng về kích thước, vịtrí. Nơ vi kích thước nhỏ hay găp nhất $(76,2 \%)$, trung bình $(14,3 \%)$, kích thước lớn $(9,5 \%)$. 26/36 bệnh nhân $(72,2 \%)$ đã được lấy bỏ

*Trường Đại học Y Hà Nội.

Chịu trách nhiệm chính: Chanthavy Souksavarn.

Email: c.souksavarn@gmail.com

Ngày nhận bài: 10/7/2021

Ngày phản biên khoa học: 7/8/2021

Ngày duyệt bài: 25/8/2021 hoàn toàn thường bằng kỹ thuât giãn da tự nhiên đối với no vi kích thước nhỏ và trung bình, nơ vi kích thước lớn phải phẫu thuật nhiều lần. Bệnh nhân phẫu thuât 1 lần $29 / 36$ nơ vì $(80,5 \%), 2$ lần $5 / 36$ nơ vì $(13,8 \%), 3$ lần $2 / 36$ nơ vi $(5,7 \%)$. Phương pháp tạo hình giãn da tự nhiên 40/54 lần phẫu thuật (70\%) các vạt tại chỗ $7 / 54(12,9 \%)$, ghép da dày $5 / 54$ $(9,8 \%)$, vạt lân cân và vat tổ chứcgiãn chiếm tỉ lế ít hơn. Kễt quả gần tốt $(8 \dot{6}, 7 \%)$, trung bình $(13,3 \%)$. Sau phẫu thuật 3-6 tháng, kết quả tốt $86,1 \%$, trung bình $13,9 \%$ và không có trường hợp nào kết quả kém. Biến chứng chủ yếu seo lồi $6 / 36(5,5 \%)$, co kéo vùng mặt với mức độ nhẹ 6/36 (5,5\%). Như vậy, giãn da tự nhiên là một trong những kỹ thuật đơn giản, hiệu quả áp dụng nhiều vùng mặt cô. Kỹ thuật vạt hay giãn da ít được sử dụng hơn và thường dùng với những tổn thương lớn và nhiều đơn vị. Tư khóa: Nỡ vi hắc tố bẩm sinh, cắt u, giãn da tự nhiên, vạt tại chỗ. 